\title{
AC 2009-1366: CONSIDERING THE MATHEMATICAL APPROACH AND COURSE-CONTENT STRUCTURE WHEN TEACHING PHYSIOLOGY TO BIOMEDICAL ENGINEERS
}

\section{Regina Nelson, University of Wisconsin, Madison}

Regina Nelson is a doctoral student in Biomedical Engineering at the University of Wisconsin-Madison. She received an M.Ed. in Special Education from the University of Pittsburgh and an M.S. in Biomedical Engineering from the University of Wisconsin-Madison. Her research focuses on teaching methods and assessment of learning outcomes related to the physiology sub-curriculum in biomedical engineering education.

\section{Naomi Chesler, University of Wisconsin, Madison}

Naomi Chesler is an Associate Professor of Biomedical Engineering at the University of Wisconsin-Madison. She received her B.S. in General Engineering from Swarthmore College, M.S. in Mechanical Engineering from MIT and Ph.D. in Medical Engineering from the Harvard-MIT Division of Health Sciences and Technology. Her research focuses on the computational and experimental study of fluid behavior within mammalian biology and effects on biomechanical properties of vascular tissues. Dr. Chesler teaches biofluid dynamics at the undergraduate and graduate levels. 


\title{
Considering Mathematical Approach and Course Content Structure When Teaching Physiology to Biomedical Engineers
}

\begin{abstract}
Although a core content area in the curriculum, physiology is presented to undergraduate biomedical engineering (BME) students in many ways. Even as a standalone course, the mathematical approach and the way the content is structured vary greatly between programs. How physiology is taught can affect how students learn subsequent topics in advanced engineering courses. An engineering standpoint suggests that physiology courses structured around key concepts taught with a quantitative slant will best prepare undergraduate BME students. The aim of our research is experimentally evaluating this conjecture. Physiology content prerequisite for a biofluids challenge lesson is presented to study participants using four different approaches: quantitative, concepts-based; quantitative, systems-based; qualitative, concepts-based; or qualitative, systems-based. After completing the physiology training, study participants engage in independent and collaborative learning via online challenge learning experiences where adaptive expertise in physiology is assessed. This paper focuses on the development of the physiology training modules and the biofluids challenge module used as a data collection environment to assess levels of adaptive expertise in physiology.
\end{abstract}

\section{Introduction}

Physiology is a core topic in undergraduate biomedical engineering (BME) programs. It is a key subject for students whether their intention is to practice medicine, work in industry or do biomedical research. BME programs utilize different strategies to satisfy ABET accreditation criteria related to physiology. A 2008 review of accredited programs shows that $49 \%$ require a standalone physiology course offered by the BME department, while $41 \%$ utilize life science departments to teach physiology to their engineering students. One program requires students take physiology courses from both biomedical engineering and biology departments. Eight percent of undergraduate BME programs do not require a specific course in physiology at all. Of those that do, the number of credit hours ranges from three to twelve (Figure 1$)^{1}$.

The ABET criteria require that biomedical engineering program graduates have the capability to understand biology and physiology and apply advanced mathematics, engineering and science to solve problems where engineering and biology interface ${ }^{2}$. Meeting this criterion typically requires a physiology sub-curriculum in BME programs. Enhancing the physiology subcurriculum also benefits students in other engineering disciplines. The Engineer of 2020 in any discipline will require a basic knowledge of physiological and biological systems as technology and life sciences continue to converge ${ }^{3}$. 


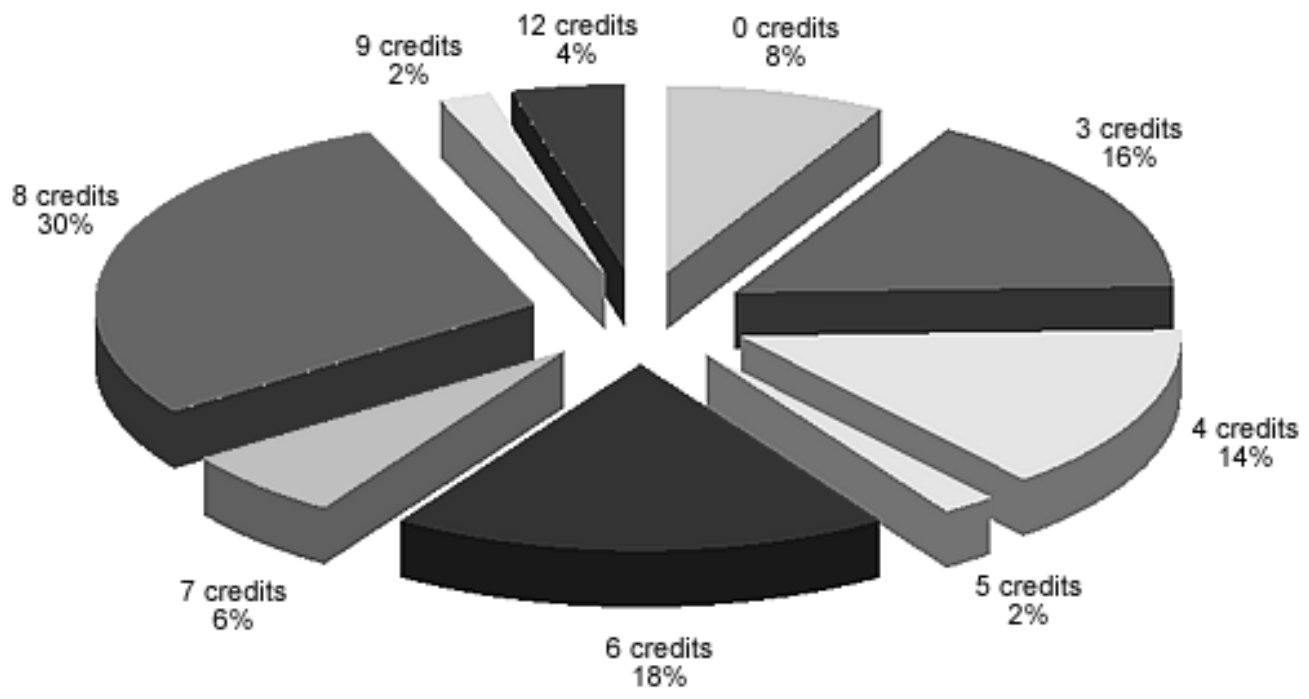

Figure 1. Number of physiology credits required in programs with ABET accreditation in $\mathbf{2 0 0 8}^{1}$

As BME programs have evolved to incorporate physiology into the undergraduate curriculum, two basic patterns have emerged. The first approach is to have students take a course offered by a life sciences department alongside students in other disciplines (i.e. pre-medical, biology, or nursing). In these courses, students receive in-depth exposure to physiology; however, the content is rarely presented using quantitative or mathematical descriptions. The second approach utilizes engineering faculty to teach a physiology course. These courses often emphasize areas related to faculty strengths and interests. Although they tend to be highly quantitative, the course may minimize the importance of, or even skip entirely, some physiology systems, thereby failing to give students a broad understanding of physiology concepts and processes they may encounter during their career ${ }^{4}$. Industry wants engineers who are able to combine the worlds of engineering and medicine and have a breadth of physiology knowledge ${ }^{5,6}$. Physiology is an entire discipline and no BME student will have the ability to cover the field in its entirety during their undergraduate tenure. Consequently, an important objective of the physiology sub-curriculum is to provide students with enough understanding of physiology that they can acquire further knowledge when they need it.

The mathematical approach used in teaching physiology falls at different points along a Qualitative - Quantitative continuum. On the one hand, physiology concepts and processes can be taught via qualitative descriptions and explanations requiring students to only occasionally engage with an algebraic expression. The quantitative approach not only involves higher math skills (e.g., algebra, calculus) but encourages students to think mathematically as they frame the process of learning physiology. 
There is another continuum that focuses on how physiology course content is structured. On one end of this continuum is the typical systems-based approach where course content is structured around human organ systems (e.g., cardiovascular, respiratory). One system is thoroughly reviewed before moving to the next. A different approach to content presentation has been proposed in which a course is structured around key concepts, and physiological systems are presented as examples of these concepts ${ }^{4,6,7}$. A physiology course taught via the concepts-based approach might, for example, develop the concept of bioelectricity and enrich learning by presenting examples where this concept occurs in various physiological systems. It would seem that physiology courses structured around key concepts and taught from a quantitative perspective are optimal for biomedical engineering students ${ }^{4,8}$. How physiology content is presented affects how BME students learn subsequent material, specifically topics in advanced engineering courses ${ }^{9}$.

This study has been designed to test different approaches to presenting the same physiology content. Undergraduate engineering students recruited for this study will complete an online training module that presents physiology content in one of four ways: Quantitative/Conceptsbased, Quantitative/Systems-based, Qualitative/ Concepts-based or Qualitative/Systems-based. After completing the randomly assigned physiology training module, participants will be assessed on how they transfer and adapt their physiology knowledge when engaging with a collaborative challenge-based learning module designed around topics in biofluids. The challenge-based learning environments have been designed to create opportunities for data collection related to participants' levels of adaptive expertise in physiology.

\section{Developing Adaptive Expertise in Physiology}

Accredited BME programs must demonstrate that graduates have an understanding of physiology and can apply advanced mathematics, science and engineering to solve problems where the life sciences and engineering interface ${ }^{2}$. Adaptive expertise is an outcome measure that has been useful in assessing student development in many biomedical engineering subdisciplines $^{10-13}$. The collaborative, challenge-based learning activities in this study are a natural environment to assess participants' levels of adaptive expertise in physiology.

One model of adaptive expertise focuses on two dimensions: knowledge and innovation. Knowledge refers to the taxonomic understanding of the field. Innovation involves the ability to perform in novel situations. Improvement in both of these dimensions allows adaptive expertise to develop ${ }^{14}$. In the biomechanics domain, a metric has been formulated to calculate weighted components of adaptive expertise as a linear combination of factual knowledge, conceptual knowledge, and transfer of learning ${ }^{12,15}$. Factual knowledge $(\mathrm{F})$ measures the ability to retain key facts and principles. Conceptual knowledge (C) focuses on the ability to understand the 
underlying principles as well as using quantitative skills to solve a problem. Transfer (T) is the ability to extend knowledge to a new situation. The metric was originally proposed to calculate adaptive expertise in biomechanics by measuring changes in student achievement based on these three elements. The weightings of the original metric were refined to reflect the linear combination that maximally separated two groups of biomechanics students based on their levels of adaptive expertise ${ }^{15}$.

The resulting metric $(\mathrm{AE}=0.14 \mathrm{~F}-0.36 \mathrm{C}+1.27 \mathrm{~T})$ is a starting point for quantifying adaptive expertise in physiology in this study. However, there are limitations in quantifying a concept like adaptive expertise. The qualitative data collected in this study will allow examination of the weighted elements of the metric as well as other factors that might contribute to adaptive expertise in physiology. The collaborative, challenge-based activities in this study provide opportunities for qualitative and quantitative assessment of how participants learn new physiology knowledge and innovatively use that knowledge.

\section{Mathematical Approach to Teaching Physiology}

Biomedical engineering programs have long recognized the need for strong overlap between mathematics and life science, particularly physiology concepts. In recent years, the need to integrate more math into physiology, biology and other life science courses has been recommended to help undergraduate life science students better prepare for the interdisciplinary field they will enter ${ }^{16}$. What level of mathematics is required to make a course quantitative in nature? The Bio2010 report uses the term "quantitative" to imply that mathematics and computing are essential tools in framing experimental questions, analyzing experimental data, generating models, and making testable predictions.

From an engineering standpoint, a quantitative approach should benefit students by creating a framework for thinking mathematically about physiology. Thinking mathematically involves an appreciation for the abstractions of mathematics and possessing the competence to use the skills. The mathematical knowledge base and the opportunity to engage in mathematical activities are important, but so are problem solving strategies, effective use of resources, and mathematical beliefs and affects. These metacognitive processes help students apply what they know about mathematics to problems encountered in other subject areas ${ }^{17,18}$.

Biomedical engineering students typically have taken at least two semesters of calculus before they are scheduled to take their first physiology course. The suggested matriculation semester for the first recommended or required physiology course is third semester or higher for $98 \%$ of the ABET-accredited programs ${ }^{1}$. Engineering students have the mathematical knowledge base to engage in physiology courses that utilize their quantitative skills. These students may also prefer to think mathematically when they approach any problem-solving task. Engineering students are engineering students because they enjoy and have excelled in quantitative courses and activities. 
Approaching learning situations and problem-solving mathematically is a preferred and effective method for engineering students.

Despite the obvious fit that biomedical engineering programs and quantitatively-based physiology courses seem to make, quantitative courses in physiology are still quite rare. Biomedical engineering is a relatively young discipline. Undergraduate programs are in various states of development and a common core curriculum is still evolving. Many programs have limited resources and faculty to teach their own departmental physiology courses. Taking advantage of more qualitatively-oriented physiology courses is an economic necessity.

\section{Structuring Physiology Course Content}

Organizing course content requires at least two decisions - what topics to include and in what order to present them. A complete presentation of all physiology topics is not feasible or necessarily appropriate in the biomedical engineering curriculum. Physiology courses are in the curriculum to advance the ability of the graduates of a BME program to solve problems at the engineering-life science interface. How students put the initial building blocks of physiology knowledge together affects how they learn subsequent topics in their field. Academia and industry agree on what physiology topics are most important for students/graduates. The most highly rated concepts come from topics in cellular, cardiovascular, neural, respiratory and renal physiology ${ }^{6}$.

When structuring content, most physiology courses and textbooks use a systems taxonomy (Table 1). This approach may have evolved as medical students need to fully understand each physiological system. Learning each system completely may be advantageous to biomedical engineering students who move onto careers in medicine or medical instrumentation; however, in one or two courses it is not possible to present the extensive content of a systems physiology taxonomy.

Table 1. Systems-based taxonomy for human physiology courses

\begin{tabular}{|l|l|}
\hline \hline Homeostasis: A Framework for Human Physiology & Sensory Physiology \\
\hline Chemical composition of body & Efferent Peripheral Nervous System \\
\hline Cells and Tissues & Skeletal-Muscular System \\
\hline Membrane Dynamics & Control of Body Movement \\
\hline Cardiovascular System & Endocrine System \\
\hline Blood Components, Flow and Pressure & Metabolism and Energy Balance \\
\hline Respiratory System & Digestive System \\
\hline Renal System & Immune System \\
\hline Nervous System & Reproductive System \\
\hline Central Nervous System & \\
\hline \hline
\end{tabular}


Systems-based physiology courses do not inherently promote an understanding of the broad concepts that govern physiology. Using a concepts-based taxonomy, a course is structured around key concepts (Table 2). Physiological systems are used to provide examples of where these concepts occur or apply to various systems. The set of key concepts may vary between instructors of courses; however the key to this approach is that the system examples do not obscure the key concepts which are the focus ${ }^{7}$.

It has been shown that as few as seven general concepts can provide students with a framework for understanding most physiological systems ${ }^{19}$. A concepts-based approach can help students become better physiological problem-solvers with an ability to predict responses of physiology systems with which they are unfamiliar based on what they know about the underlying concepts. Structuring content in a different way, a concepts-based taxonomy emphasizes unifying principles and concepts that repeat across physiology systems ${ }^{4,20}$. These unifying concepts have been adapted as the basis for the concepts-based taxonomy in the present study.

Table 2. Basic principles and unifying themes which repeat across physiological systems and create a concepts-based taxonomy ${ }^{4,20}$

\begin{tabular}{|l|l|}
\hline \hline INTRODUCTORY CONCEPTS & Homeostasis/dynamics and control systems \\
& Communication and coordination \\
& Bioelectricity \\
& Biological energy \\
& Biological transduction (molecular/sensory) \\
& Molecular interactions \\
\hline ENGINEERING CONCEPTS & Heat balance \\
& Mass balance \\
& Mass flow (transport) \\
& Pressure - flow - resistance \\
& Mechanics: movement and associated forces \\
& Elastic properties \\
\hline ANATOMICAL CONCEPTS & Structure/function relationships \\
& Levels of organization in the body \\
& Compartmentation \\
\hline BIOLOGICAL CONCEPTS & Emergent properties of complex systems \\
& Scaling in biological systems \\
& Physiological variables \\
& Biological units of measure \\
\hline \hline
\end{tabular}

\section{Creating Testable Physiology Learning Modules}

In this study, the main and interaction effect of mathematical approach and course content structure will be tested with four physiology training modules. Online collaborative, challengebased learning modules will be used to collect data related to adaptive expertise in physiology. The prerequisite physiology content for the challenge modules will be presented in one of four 
ways: quantitative, concepts-based; quantitative, systems-based; qualitative, concepts-based; or qualitative, systems-based. A small subset of physiology content was determined prerequisite knowledge for engaging with the collaborative challenge module (Figure 2). This content includes subtopics related to factual and conceptual knowledge of the human cardiovascular system and principles of blood pressure.

To create testable physiology learning modules, the content was parsed according to a systemsbased and concepts-based taxonomy. Although the systems are not presented in their entirety, elements from the following systems are included in the physiology training: cells and tissues; cardiovascular system; and blood components, flow and pressure. The background physiology knowledge requires an understanding of the following concepts: homeostasis/dynamics and control systems; communication and coordination; mass flow/transport; pressure, flow and resistance; structure/ function relationships; biological units of measure; and physiological variables.

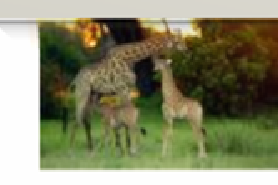

\section{The Challenge}

You are one of a small group of interns working at the Zumahavi Wildlife Park. The park has just received word that they are about to receive a large donation from Thurston and Lovey Howell to build a new habitat for the giraffes in the park. There is one slight problem. Lovey Howell is reluctant to give the money to Zumahavi because she is concerned about the welfare of the giraffes. She insists that the water and feeding troughs for the giraffe habitat be placed 12 feet in the air so the giraffes do not have to lower their heads to take nourishment. It is up to the interns to present scientific evidence to convince Mrs. Howell that placing food and water at head level for the giraffe is not necessary as the giraffes will not be distressed when they bend their heads to eat or drink.

You will soon begin working with the other interns on this important challenge. First you need to review some important physiology concepts. You will do this by working through the physiology training module described in the next topic.

Figure 2. Screenshot of challenge presented to study participants as they begin the challenge-based collaborative learning module prior to the physiology training

The lessons in the systems-based training are organized according to systems. The topics related to cells and tissues are first presented, then the cardiovascular system, and finally the prerequisite blood components, flow and pressure topics. Content related to the different physiology concepts can occur in any of the systems lessons. For instance, in order to begin to develop the learner's understanding of homeostasis/dynamics and control systems, this concept is introduced in the 
Cells and Tissues Lesson. The concept is again referred to and developed in the Cardiovascular System Lesson. Information about concepts may occur in one, some or all of the lessons in the systems-based learning modules.

In the concepts-based learning modules, the lessons are organized around the concepts. For example, the homeostasis and control systems concept is presented in a single lesson. To bolster the learner's understanding of homeostasis, examples of homeostasis in cells, blood and the cardiovascular system, in general, are provided in the lesson. Informational content about specific systems are pulled into the lessons as they relate to the concept. Factual and conceptual information about a particular system may appear in one, some, or all of the lessons.

Establishing the dichotomy of a concepts-based and systems-based framework for the learning modules is clearer than determining what makes a quantitative approach and what makes a qualitative approach to teaching physiology. Even when a physiology course is defined to be qualitative, there are some quantitative elements. The reverse is also true. A quantitative course will have material that is presented qualitatively. There is, indeed, a quantitative - qualitative continuum by which mathematical approach to teaching physiology can be assessed. The mathematical approach used in physiology courses can fall at many different points along the continuum.

In the extreme, a purely qualitative course in physiology probably does not exist at the collegiate level. Most courses have an accompanying lab section where students are guided through simulations and other quantitative activities. Typically, the mathematical skills required for these lab activities do not extend beyond simple algebra. Simulations are often "canned applications" and students are guided through the lab exercises with limited opportunity for free exploration.

This type of course forms the basis of the qualitative model for the physiology training modules in this study. Qualitative descriptions are used to present physiology content. If an algebraic formula is used, it is only introduced after the expression has been stated with words. Any simulation activity is presented with detailed guidelines as to which variables need to be used to obtain the anticipated results.

At the other end of the spectrum, a purely quantitative physiology course probably does not exist either. Physiology is a topic that requires some qualitative descriptions and explanations. How does the heart pump blood throughout the body? What happens when humans experience a painful stimulus? Answers to these questions cannot be thoroughly explained with numbers and mathematical thinking. A quantitative approach to teaching physiology will invariably include some qualitative elements. 
Quantitative thinking revolves around relationships and measurements. Presentation tools that shape this focus include models, simulations, graphs, diagrams, and concept maps. When appropriate, mathematical expressions, including integrals and derivatives, are used in content presentation. Given the breadth of the topics that must be covered in a BME physiology course and the limited depth at which these topics can be explored, advanced mathematical expressions are not always the best tools. It is important, though, to establish a framework on which a mathematical expression can always be built. Understanding is fostered by giving context to physiological quantities and integrating them into a whole. Table 3 summarizes how the physiology content that supports a particular learning objective is presented both qualitatively and quantitatively.

Table 3. Summary of the qualitative and quantitative presentation of physiology content supporting a learning objective for the physiology training modules used in the study

Objective: Define and describe factors that influence stroke volume and cardiac output.

Questions: What is stroke volume? Cardiac output? What factors control cardiac output?

Acceptable Evidence of Understanding: (1) Define cardiac output and stroke volume. (2) Given a scenario, assess how cardiac output can be increased.

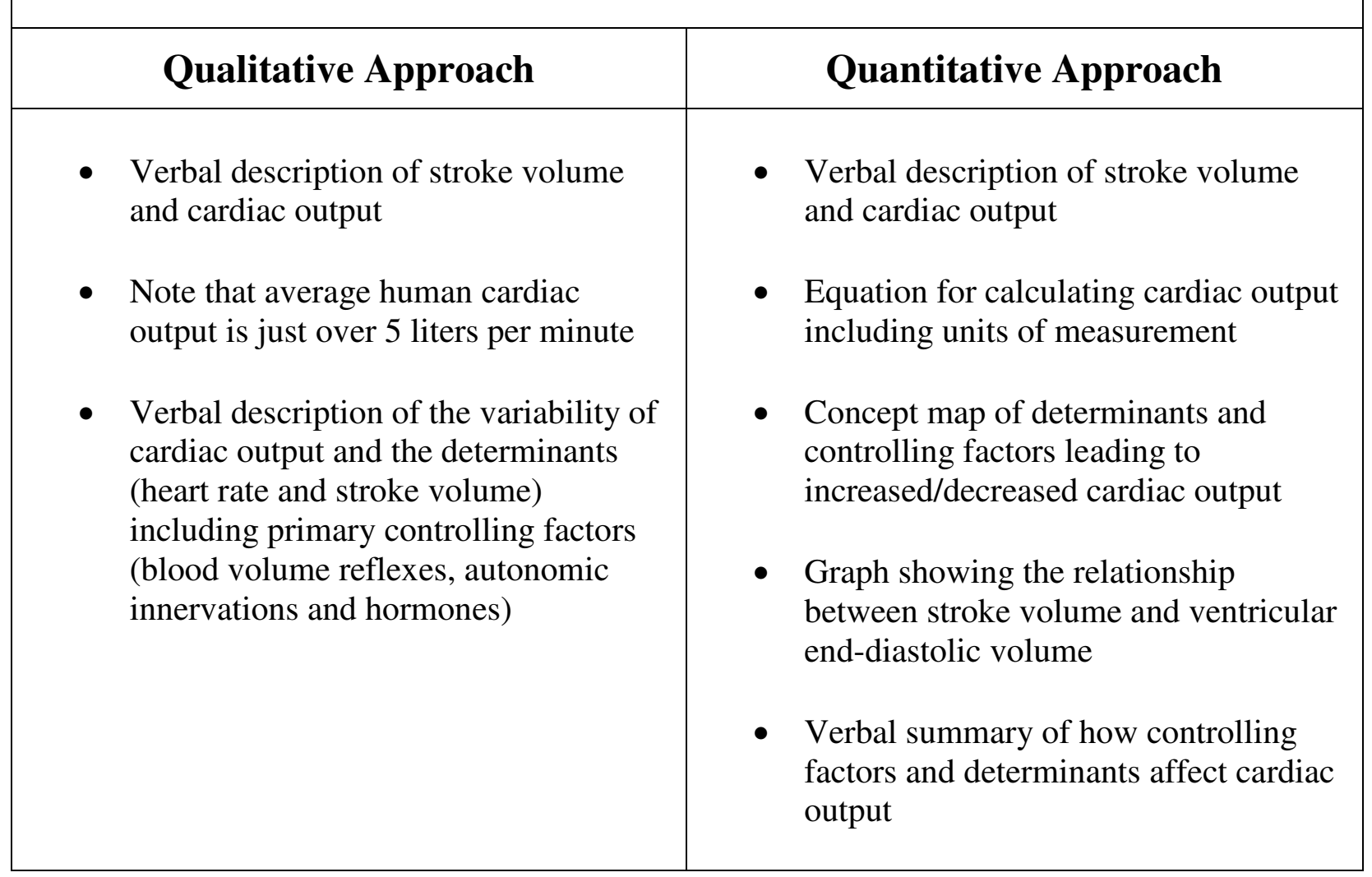




\section{Study Methods}

This study has been designed using a randomized $2 \times 2$ factorial design to evaluate the conjecture that a concepts-based, quantitative approach best prepares biomedical engineering students for future learning in their highly interdisciplinary field.

\begin{tabular}{c|c|c|}
\multicolumn{2}{c}{ COURSE STRUCTURE / TAXONOMY } \\
\cline { 2 - 3 } $\begin{array}{c}\text { MATHEMATICAL } \\
\text { APPROACH }\end{array}$ & $\begin{array}{c}\text { Quantitative, Concepts-based } \\
\text { Physiology Training }\end{array}$ \\
Physiology Training \\
\cline { 2 - 3 } & $\begin{array}{c}\text { Quantitative, Concepts-based } \\
\text { Physiology Training }\end{array}$ & $\begin{array}{c}\text { Qualitative, Systems-based } \\
\text { Physiology Training }\end{array}$ \\
\hline
\end{tabular}

Figure 3. Randomized, $2 \times 2$ factorial design with independent groups to test hypothesis that mathematical approach and/or course structure affect development of adaptive expertise in physiology

Participants for the study will be recruited from students pursuing or intending to pursue a degree in the College of Engineering. To be considered for participation in the study, the individual must have taken two semesters of college calculus or the equivalent (i.e., AP Placement courses). Students who have taken a college-level or AP physiology course will not be included. Although students who express an interest in life science or biomedical engineering topics will be targeted, the study will not be limited to engineering students in the BME department.

Forty-eight participants will be assigned to the four experimental groups creating four cohorts of three participants in each condition. The individuals in each cohort will be enrolled in the study at the same time and collaborate on some of the challenge activities. The physiology training modules, however, will be completed by each participant independently. Each member of the cohort will receive the same type of physiology instruction (e.g., Qualitative, Concepts-based).

When the participant first accesses the module created using the learning management system Moodle ${ }^{\mathrm{TM}}$, the challenge is presented and the role-playing simulation is introduced. The participant is then directed to take the physiology training (see Figure 2). A pre-assessment and post-assessment will be administered directly before and after the physiology training. After completing the assigned physiology training, the series of challenge activities continue following the STAR.Legacy Cycle format ${ }^{20}$.

Participants are led through a series of activities to guide them as they "generate ideas" about the challenge. These include contributing opinions in an online discussion forum, participating in a virtual brainstorming meeting with the cohort in an online conference room, and responding to survey questions posed by the learning facilitator. The virtual world Second Life ${ }^{\mathrm{TM}}$ is used as a meeting environment for collaborative activities. Using avatars, participants enter an online 
conference room specifically developed for the study where they can chat with others in their cohort or with members of the research team.

After brainstorming potential solutions, participants are directed to "seek multiple perspectives" to "research and revise" their original ideas by completing online lessons that guide a solution to the challenge (Figure 4). Article summaries and research articles related to the topic are readily available for participants to access within the Moodle ${ }^{\mathrm{TM}}$ environment.

In the final stages, the participants are asked to "test their mettle" and "go public" as they try out their solutions to the challenge when the cohorts meet again in Second Life ${ }^{\mathrm{TM}}$ to revise their final proposal and present their final thoughts on the challenge.

This online format, using both Moodle ${ }^{\mathrm{TM}}$ and Second Life ${ }^{\mathrm{TM}}$, presents many opportunities for assessing adaptive expertise in physiology through both quantitative and qualitative data collection. The online model allows unique insight into how the participants are learning and how they transfer their new knowledge. An online footprint can be tracked which lets the researcher unobtrusively observe the learning process and interaction between members of the cohort. Moodle ${ }^{\mathrm{TM}}$ was opted as the learning management system for this study in part because it is open source and has a large community of educators working to evolve its use in online education.

Throughout the challenge modules, expressions of factual knowledge, conceptual knowledge and transfer of physiology content presented in the training will be collected and analyzed. Traditional quantitative assessments are included in quizzes associated with each lesson, as well as in "Initial Thoughts" and "Final Thoughts" about the challenge that participants are directed to write. The Moodle ${ }^{\mathrm{TM}}$ online learning environment lends itself to tracking many different quantitative measures that relate to learning. How many different "initial ideas" did the participant express in the discussion forum? How many different physiology concepts did the participant mention in the chat transcripts from the online brainstorming meeting? How much time did the participant take to complete each online lesson? How many attempts did the participant need to correctly answer a question in a lesson? How many of the online resources did the participant access while working on the lessons or during the course of the challenge experience?

Not negating the importance of numbers used to quantify adaptive expertise, using the online challenge module as a data collection environment also allows for rich qualitative data collection. Observations of the discussion posts and the virtual meetings allow the researcher to see how the participant expresses factual and conceptual physiology knowledge and the innovative ways they use that knowledge to solve a problem in a novel situation. All interactions between the participants are collected in the online record of individual activity in Moodle ${ }^{\mathrm{TM}}$ and 
in the chat transcripts of Second Life ${ }^{\mathrm{TM}}$. Using a data analysis technique like modified analytic induction to compare and contrast the qualitative data collected from the participants, we can begin to identify themes and categories of how participants learn and see if that generalizes across type of mathematical approach or course content structure.

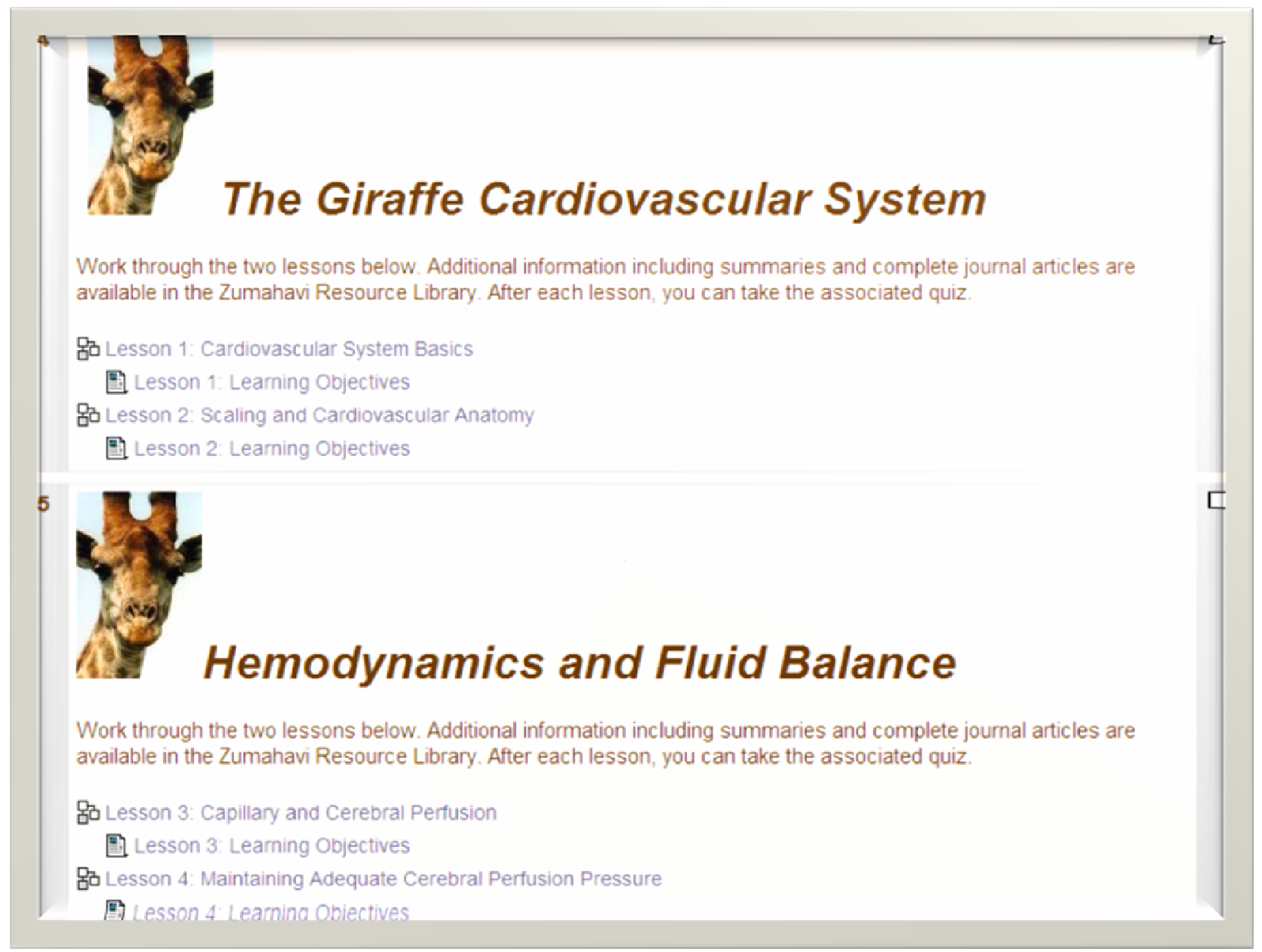

Figure 4. Screenshot of lesson topics presented to study participants in the challenge-based collaborative learning module

\section{Future Work}

An online, collaborative challenge-based learning module with four experimental physiology training modules has been designed and developed as an online learning experience using the learning management system Moodle ${ }^{\mathrm{TM}}$. The challenge and physiology training modules have been evaluated by students enrolled in a physiology course at a major university. These participants were from many different departments, including biomedical engineering, healthrelated professions, and life sciences. Pilot tests with engineering students who have not taken a 
physiology course are in process to fine-tune the assessments in order to optimize quantitative and qualitative data collection procedures for the study.

Physiology is a core content area in the biomedical engineering curriculum. The physiology learning modules developed through this work provide a vehicle for examining and evaluating different approaches to teaching physiology. Biomedical engineering education can be improved as more is discovered about how students learn physiology and subsequently apply that knowledge as they approach new topics and learning opportunities within their discipline.

\section{Bibliography}

1. Nelson, R.K. (2008). Physiology and the biomedical engineering curriculum: How approaches to physiology instruction advance subsequent learning of BME topics. Unpublished report.

2. ABET Engineering Accreditation Commission (2007). Criteria for accrediting engineering programs.

3. National Academy of Engineering (2004). The engineer of 2020. Washington DC: The National Academies Press.

4. Silverthorn, D.U. (2002). Developing a concepts-based physiology curriculum for bioengineering: A VaNTH project. Second Joint EMBS/BMES Conference. Houston, TX: IEEE.

5. Linsenmeier, R.A. (2003). What makes a biomedical engineer? IEEE Engineering in Medicine and Biology Magazine, 22(4), 32-38.

6. Linsenmeier, R.A. \& Gatchell, D.W. (2008) Physiology concepts and physiology problems for biomedical engineering students. ASEE Annual Conference and Exposition. Pittsburgh, PA: ASEE.

7. Feder, M.E. (2005). Aims of undergraduate physiology education: A view from the University of Chicago. Advances in Physiology Education, 29:3-10.

8. Troy, J.B. \& Linsenmeier, R.A. (2003). Optimizing the delivery of content in physiology instruction. IEEE Engineering in Medicine and Biology Magazine, 22(4), 80-87.

9. Bransford, J., Brown, A.L. \& Cocking, R.R. (Eds). (1999). How people learn: Brain, mind, experience and school. Washington, DC: National Academy Press.

10. Fisher, F.F. \& Peterson, P. (2001). A tool to measure adaptive expertise in biomedical engineering students. ASEE Annual Conference and Exposition. Albuquerque, NM: ASEE.

11. Harris, T.R., Bransford, J.D. \& Brophy, S. (2002). Roles of learning sciences and learning technologies in biomedical engineering education: A review of recent advances. Annual Review of Biomedical Engineering,4, 20-48.

12. Pandy, M.G., Petrosino, A.J., Austin, B.A. \& Barr, R.E. (2004). Assessing adaptive expertise in undergraduate biomechanics. Journal of Engineering Education, 93(3): 211-222.

13. Martin, T., Rayne, K., Kemp, N.J., Hart, J. \& Diller, K.R. (2005). Teaching for adaptive expertise in biomedical engineering ethics. Directions for Teaching and Learning, 108: 35-47.

14. Martin, T., Rivale, S.D., \& Diller, K.R. (2007). Comparison of student learning in challenge-based and traditional instruction in biomedical engineering. Annals of Biomedical Engineering, 35(8): 1312-1323.

15. Petrosino, A.J., Svihla, V. \& Kapur, M. (2006). Calculating expertise in bioengineering education. $9^{\text {th }}$ International Conference on Engineering Education. San Juan, PR.

16. National Research Council (2002). Bio2010: Transforming undergraduate education for future research scientists. 
17. Schoenfeld, A.H. (1992). Learning to think mathematically: Problem solving, metacognition and sense-making in mathematics. Handbook for research on mathematics teaching and learning. New York: MacMillan.

18. Cardella, M. (2007). What your engineering students might be learning from their mathematics pre-reqs (beyond integrals and derivatives). $37^{\text {th }}$ ASEE/IEEE Frontiers in Education Conference. Milwaukee, WI.

19. Modell, H.I. (2000). How to help students understand physiology. Advances in Physiology Education, 23(1): 101-107.

20. VaNTH (2007). VaNTH ERC. Retrieved 6/1/07 from VaNTH Website: http://www.vanth.org

21. Schwartz, D.L., Brophy, S. Lin, X. \& Bransford, J.D. (1999). Software for managing complex learning:

Examples from an educational psychology course. Education Technology Research and Development, 47(2): 33-59. 